\title{
Treatment of Severe Renal Disease in ANCA Positive and Negative Small Vessel Vasculitis with Rituximab
}

\author{
Shivani Shah ${ }^{a}$ Zdenka Hruskova $^{c}$ Marten Segelmark ${ }^{d}$ Matthew D. Morgan ${ }^{e}$ \\ Jonathan Hogan $^{\text {b Steven K. Lee }}{ }^{\text {a }}$ Jessica Dale ${ }^{f}$ Lorraine Harper $^{\mathrm{e}}$ \\ Vladimir Tesar $^{c}$ David R.W. Jayne ${ }^{g}$ Duvuru Geetha ${ }^{a}$ \\ ${ }^{a}$ Department of Medicine, Johns Hopkins University, Baltimore, Md., ${ }^{b}$ Department of Medicine, Hospital of the

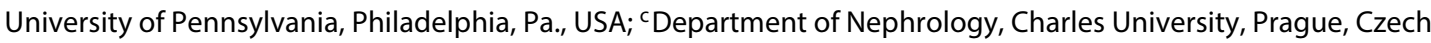 \\ Republic; ${ }^{d}$ Department of Medicine, Linköping University, Linköping, Sweden; ' University of Birmingham and \\ fSchool of Immunity and Infection, College of Medical and Dental Sciences, University of Birmingham, Birmingham, \\ ${ }^{9}$ Vasculitis and Lupus Clinic, Addenbrooke's Hospital, Cambridge, UK
}

\section{Key Words}

Rituximab - ANCA vasculitis - Severe renal disease

\begin{abstract}
Background/Aims: Rituximab and glucocorticoids are a non-inferior alternative to cyclophosphamide and glucocorticoid therapy for induction of remission in antineutrophil cytoplasmic antibody (ANCA) associated vasculitis (AAV) patients with moderate renal disease. The efficacy and safety of this approach in patients with severe renal impairment are unknown. We report the outcomes and safety profile of rituximab and glucocorticoid therapy for induction of remission in patients with AAV and ANCA-negative vasculitis presenting with severe renal disease. Methods: A multicenter, retrospective, cohort study was conducted between 2005 and 2014. Patients with new or relapsing disease with an estimated glomerular filtration rate (eGFR) of $\leq 20 \mathrm{ml} /$ $\min / 1.73 \mathrm{~m}^{2}$ treated with rituximab and glucocorticoid induction with or without plasmapheresis were included. Fourteen patients met the inclusion criteria. The primary outcomes were rate of remission and dialysis independence at 6 months. The secondary outcomes were eGFR at
\end{abstract}

6 months, end-stage renal disease (ESRD), survival rates and adverse events. Results: All patients were Caucasian, and $57 \%$ were male. The mean eGFR was $12 \mathrm{ml} / \mathrm{min} / 1.73 \mathrm{~m}^{2}$ at diagnosis. All patients achieved remission with a median time to remission of 55 days. Seven patients required dialysis at presentation of which 5 patients recovered renal function and discontinued dialysis by 6-month follow-up. The mean eGFR for the 11 patients without ESRD who completed 6-month follow-up was $33 \mathrm{ml} / \mathrm{min} / 1.73 \mathrm{~m}^{2}$. Four patients ultimately developed ESRD, and one died during the follow-up period. Conclusion: Patients with AAV and severe renal disease achieve high rates of remission and dialysis independence when treated with rituximab and glucocorticoids without cyclophosphamide.

(c) 2015 S. Karger AG, Basel

\section{Introduction}

Antineutrophil cytoplasmic antibody (ANCA) associated vasculitis (AAV) is the most common cause of rapidly progressive glomerulonephritis. Approximately, 75$90 \%$ of patients with ANCA vasculitis develop renal in-

\section{KARGER 125}

(C) 2015 S. Karger AG, Base

0250-8095/15/0415-0296\$39.50/0

E-Mail karger@karger.com

www.karger.com/ajn
Duvuru Geetha, MD, MRCP (UK)

Department of Medicine

Johns Hopkins University School of Medicine

Baltimore, MD 21224 (USA)

E-Mail gduvura@jhmi.edu 
volvement during the course of their disease [1]. Immunosuppression is indicated regardless of degree of renal dysfunction, especially given that more than half of patients with an estimated glomerular filtration rate (eGFR) of $<10 \mathrm{ml} / \mathrm{min} / 1.73 \mathrm{~m}^{2}$ recover substantial renal function with treatment [2]. Standard treatment for induction of remission includes cyclophosphamide and glucocorticoid therapy with or without plasmapheresis [3]. Unfortunately, about half of patients develop relapsing disease, and exposure to cyclophosphamide increases the risk of infections, cytopenia, infertility, bladder toxicity and malignancy. Given, the central role of B-cells in the pathogenesis of AAV, B-cell depleting agents were tested as an alternative treatment strategy [2].

The RAVE [3] and RITUXVAS [4] trials validated the use of a B-cell depleting agent, rituximab, for remission induction in AAV with subsequent FDA approval for this indication in April 2011. However, all patients with severe renal involvement also received cyclophosphamide in the RITUXVAS trial or were excluded per the RAVE trial. The KDIGO guidelines, which preceded the RAVE and RITUXVAS trials, recommend the use of rituximab in the absence of severe renal disease [5]. Thus, outcomes in patients with severe renal involvement treated solely with rituximab and glucocorticoids for remission induction have not been reported. We present the clinical outcomes in 14 patients with severe renal impairment (eGFR $\leq 20 \mathrm{ml} /$ $\mathrm{min} / 1.73 \mathrm{~m}^{2}$ by modification of diet in renal disease (MDRD) equation) secondary to AAV or ANCA-negative small vessel vasculitis treated with rituximab and glucocorticoids as their remission induction therapy. The safety profile of this regimen was also assessed.

\section{Methods}

\section{Study Population}

The study population was a retrospective cohort derived from 5 hospitals in the United States and Europe (Johns Hopkins Hospital Vasculitis Clinic and Columbia University, USA; Linkoping University, Sweden; University of Birmingham, Birmingham, and Addenbrooke's Hospital, Cambridge, UK) between 2005 and 2014. Patients with renal biopsy confirmed crescentic and necrotizing pauci-immune glomerulonephritis or clinically diagnosed glomerulonephritis and AAV with an MDRD eGFR of $\leq 20 \mathrm{ml} /$ $\mathrm{min} / 1.73 \mathrm{~m}^{2}$ were treated with rituximab and glucocorticoid induction therapy with follow-up until remission or death were included. All patients received 1,000 mg of intravenous solumedrol daily for 3 days followed by prednisone $1 \mathrm{mg} / \mathrm{kg} /$ day followed by a taper established by the treating physician. Rituximab was dosed either at $375 \mathrm{mg} / \mathrm{m}^{2}$ once a week for 4 weeks or 1,000 mg every 2 weeks for 2 doses. A total 11 of 14 patients received PCP prophylaxis (8 patients with trimethoprim-sulfamethoxazole, 2 patients with dapsone, and 1 patient with atovaquone). The rationale to use rituximab for induction therapy in these patients were as follows: 2 patients had myelodysplastic syndrome, 1 patient had a history of lymphoma, 4 patients chose rituximab due to their young age to preserve fertility and in 7 patients, it was due to physician preferences in the setting of relapsing disease, frailty, active infection and severe post-renal biopsy bleed requiring embolization. Patients were allowed to have plasma exchange. Patients were excluded if they had anti-glomerular basement membrane antibodies present or received cyclophosphamide induction therapy. ANCA positivity was not required for inclusion. Fourteen patients were eligible for analysis. The study protocol was approved by the institutional review boards of each institution.

\section{Data Acquisition}

Clinical Data

Age, gender, disease phenotype, ANCA type, new versus established diagnosis and clinical features at presentation were ascertained. eGFR at presentation, 6-month and last follow-up, occurrence of disease relapse, need for renal replacement therapy at the time of presentation and at last follow-up, the dosing of rituximab and number of sessions of plasmapheresis (if applicable) were extracted from review of clinical source documents. Adverse events including recorded rituximab infusion reaction, episodes of leukopenia $\left(\mathrm{WBC}<4,000 / \mathrm{mm}^{3}\right.$ ) and infections requiring hospitalization were recorded.

\section{Laboratory Data}

Peak serum creatinine, erythrocyte sedimentation rate and $\mathrm{C}$-reactive protein at the time of diagnosis were recorded. Available data on urine protein quantification data at the time of diagnosis was documented. ANCA testing was done by standard indirect immunofluorescence assay on ethanol fixed neutrophils for cytoplasmic ANCA (c-ANCA) and perinuclear ANCA (p-ANCA). PR3 and myeloperoxidase (MPO) testing by direct enzyme linked immunosorbent assay (ELISA) was performed according to the local laboratory. If the testing for c-ANCA, p-ANCA, PR3 ELISA and MPO ELISA was negative, patients were labeled as having ANCA-negative vasculitis. Renal biopsy was classified according to the International Working Group of Renal Pathologists (IWGRP) class based on paper reports by the individual centers. Available data on B-cell counts and presence of hypogammaglobulinemia were recorded.

\section{Outcomes}

The primary outcomes were (1) remission rates at 6 months after treatment with rituximab and glucocorticoids and (2) renal recovery after acute dialysis need at diagnosis. Secondary outcomes were eGFR at 6 months, development of end-stage renal disease (ESRD), patient survival and adverse events with rituximab and glucocorticoid therapy.

\section{Study Definitions}

Disease phenotype was defined according to the Chapel Hill Consensus nomenclature. Renal function was measured using the 4-variable MDRD formula for eGFR [6]. Severe renal disease was defined as MDRD eGFR of $\leq 20 \mathrm{ml} / \mathrm{min} / \mathrm{m}^{2}$. ESRD was defined by the ongoing need for renal replacement therapy for $>12$ weeks. Hematuria was defined as urinary red blood cell count of $>10$ per high power field. Kidney involvement was defined by a diagnostic renal biopsy or with the presence of active urine sediment. Remis- 
Table 1. Demographics of AAV/ANCA-negative small vessel vasculitis patients with severe renal disease treated with rituximab and glucocorticoids

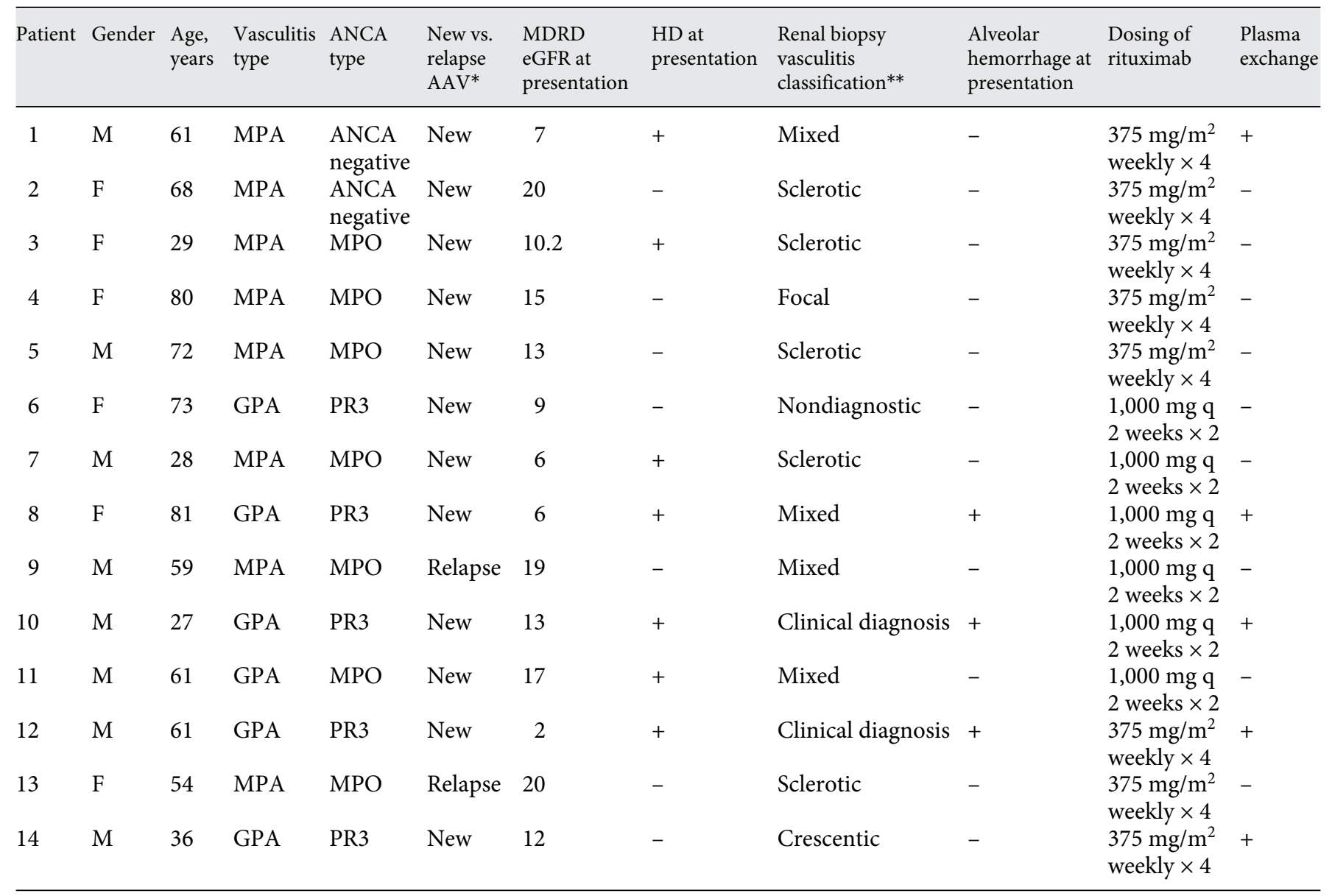

All patients were Caucasian. * Also includes ANCA-negative vasculitis patients. ${ }^{* *}$ Renal biopsy vasculitis classification based on IWGRP criteria.

sion was defined as stabilization or improvement in serum creatinine, resolution of hematuria and absence of extra-renal signs of vasculitis for at least 1 month [7]. Relapse was defined as occurrence of signs and symptoms of vasculitis in any organ requiring a change in immunosuppressive therapy after achieving remission. B-cell reconstitution was defined as presence of $>20$ CD19-positive B-cells per microliter.

All descriptive data are presented as median with range or mean with standard deviation.

\section{Results}

\section{Patient Characteristics}

Fourteen patients met the inclusion and exclusion criteria. Baseline characteristics are illustrated in table 1. All were Caucasian, and the majority were male. Median age at diagnosis was 61 years. Twelve had a new diagnosis of vasculitis. Seven patients (50\%) were MPO ANCA positive, 5 patients were PR3 ANCA positive and 2 patients were ANCA negative. The mean eGFR (SD) at diagnosis was $12(6) \mathrm{ml} / \mathrm{min} / 1.73 \mathrm{~m}^{2}$, and the median (IQR) was $12.5(2-20) \mathrm{ml} / \mathrm{min} / 1.73 \mathrm{~m}^{2}$.

Seven patients $(50 \%)$ required hemodialysis at the time of presentation. All 7 patients were newly diagnosed. Of these patients, 1 patient was ANCA negative, 3 patients were MPO ANCA positive and 3 patients were PR3 positive. Of these, 5 patients underwent renal biopsy at the time of presentation. Three patients were classified as mixed class and 2 patients were classified as the sclerotic class by the IWGRP system.

Five patients ( 4 with GPA and 1 with MPA) received 5-7 sessions of plasma exchange. All 5 patients were new- 
Table 2. Outcomes of AAV/ANCA-negative small vessel vasculitis patients with severe renal disease treated with rituximab and glucocorticoids

\begin{tabular}{|c|c|c|c|c|c|c|c|c|c|c|c|c|}
\hline Patient & $\begin{array}{l}\text { Vasculitis } \\
\text { type }\end{array}$ & $\begin{array}{l}\mathrm{HD} \text { at } \\
\text { presentation }\end{array}$ & $\begin{array}{l}\text { Rituximab } \\
\text { course } \\
\text { completed }\end{array}$ & Remission & $\begin{array}{l}\text { MDRD } \\
\text { eGFR at } \\
6 \text { months }\end{array}$ & $\begin{array}{l}\text { Dialysis } \\
\text { independence } \\
\text { at } 6 \text { months** }\end{array}$ & $\begin{array}{l}\text { Prednisone } \\
\text { dose (in mg) } \\
\text { at } 6 \text { months }\end{array}$ & $\begin{array}{l}\text { B-cell } \\
\text { depletion } \\
\text { at } 6 \text { months }\end{array}$ & Leukopenia & $\begin{array}{l}\text { Infection } \\
\text { causing } \\
\text { hospitalization }\end{array}$ & ESRD & $\begin{array}{l}\text { Cause of } \\
\text { death (if } \\
\text { applicable) }\end{array}$ \\
\hline 1 & MPA & + & $\begin{array}{l}\text { - (lost } \\
\text { insurance } \\
\text { coverage) }\end{array}$ & + & 41 & + & 10 & + & - & & - & \\
\hline 2 & MPA & - & + & + & 22 & $\mathrm{n} / \mathrm{a}$ & 0 & Unknown & - & & + & $\begin{array}{l}\text { Clostridium } \\
\text { difficile } \\
\text { sepsis }\end{array}$ \\
\hline 3 & MPA & + & + & + & 25 & + & 5 & Unknown & - & Herpes zoster & - & \\
\hline 4 & MPA & - & + & + & 23 & $\mathrm{n} / \mathrm{a}$ & 5 & + & - & & - & \\
\hline 5 & MPA & - & + & + & 37 & $\mathrm{n} / \mathrm{a}$ & 0 & Unknown & - & $\begin{array}{l}\text { Pneumonia, } \\
\text { urinary tract } \\
\text { infection }\end{array}$ & - & \\
\hline 6 & GPA & - & + & + & 35 & $\mathrm{n} / \mathrm{a}$ & 8 & Unknown & - & & - & \\
\hline 7 & MPA & + & + & + & ESRD & - & 0 & Unknown & + & & + & \\
\hline 8 & GPA & + & + & + & ESRD & - & 10 & + & - & & + & \\
\hline 9 & MPA & - & + & + & 23 & $\mathrm{n} / \mathrm{a}$ & 5 & Unknown & - & & - & \\
\hline 10 & GPA & + & + & + & 73 & + & 5 & + & - & & - & \\
\hline 11 & GPA & + & + & + & 49 & + & 5 & + & + & & - & \\
\hline 12 & GPA & + & + & + & 9 & + & 5 & + & - & & + & \\
\hline 13 & MPA & - & + & + & $\mathrm{n} / \mathrm{a}^{*}$ & $\mathrm{n} / \mathrm{a}$ & 5 & $\mathrm{n} / \mathrm{a}$ & - & & - & \\
\hline 14 & GPA & - & + & + & 31 & $\mathrm{n} / \mathrm{a}$ & 10 & + & - & & - & \\
\hline
\end{tabular}

* Follow-up $<6$ months. ${ }^{* *}$ Dialysis independence is recorded as ' + ' if patients who required dialysis at presentation were able to regain enough renal function to discontinue dialysis at 6-month follow-up. It is recorded as '-' if patients were not able to come off of dialysis and ' $\mathrm{n} / \mathrm{a}$ ' if patients did not require dialysis at presentation.

ly diagnosed, and 4 patients required dialysis on presentation. Three patients with GPA also presented with alveolar hemorrhage. Rituximab was given following completion of plasma exchange in 4 patients. One patient received 1 dose of rituximab before starting plasma exchange and 3 doses after plasma exchange was completed.

Eight out of 14 patients received rituximab $375 \mathrm{mg} / \mathrm{m}^{2}$ weekly for 4 weeks and the remainder received 1,000 $\mathrm{mg}$ every 2 weeks for 2 doses. One did not complete their course of rituximab due to lack of coverage by medical insurance.

\section{Outcomes}

Outcomes data are summarized in table 2. The median (IQR) follow-up time was 553 (136-2,013) days. All patients achieved remission with a median time to remission of 55 (range 39-162) days. Of the 7 patients who required dialysis, 5 patients ( 3 with GPA and 2 with MPA; $71 \%$ ) recovered renal function and discontinued dialysis by 6-month follow-up. The mean (SD) eGFR of patients without ESRD was $33(17.0) \mathrm{ml} / \mathrm{min} / 1.73 \mathrm{~m}^{2}$, and the median (IQR) was $31(22-73) \mathrm{ml} / \mathrm{min} / 1.73 \mathrm{~m}^{2}$ at 6 -month follow-up. The mean (SD) increase in eGFR at 6 months among 11 patients who were not on dialysis and had follow-up data available was $21(17) \mathrm{ml} / \mathrm{min} / 1.73 \mathrm{~m}^{2}$.

Four (two with GPA and two with MPA) of 14 (29\%) patients ultimately developed ESRD during the follow-up period. Of these 4 patients, two needed dialysis at presentation (one with GPA and one with MPA) and did not recover. One MPA patient developed ESRD after 25 months due to a renal relapse, and another patient with GPA developed ESRD after 12 months.

The median prednisone dose at 6 months was $5 \mathrm{mg} /$ day (range 5-10 mg/day). B-cell counts were measured in 7 of 15 patients approximately 6 months following rituximab infusion, and all had undetectable levels of B-cells. Of the remaining 8 patients, one of them underwent Bcell measurement at 12 months and was found to have B-cell depletion.

Seven patients were started on maintenance immunosuppression after induction therapy. Three were treated with azathioprine, 3 patients were treated with rituximab and 1 patient was treated with enteric-coated mycophenolate mofetil. The remaining 7 patients did not initiate 
maintenance immunosuppression for the following reasons: 3 patients were within 1 year of induction therapy and were still B-cell depleted, 1 patient had a history of infection post rituximab, 2 patients had myelodysplastic syndrome and in 1 patient, it was due to physician's choice. One patient (7\%), who was not on maintenance immunosuppression, developed a relapse at 24 months. This patient was ANCA-negative and suffered from a severe relapse with renal involvement.

With regards to side effects of induction with rituximab and glucocorticoids, 2 patients (14\%) developed leukopenia but did not suffer from infections as a consequence. Two patients (14\%) developed infections requiring hospitalization in the first year (pneumonia and herpes zoster). A total 6 of 15 patients had their immunoglobulin levels measured. Of those 6 patients, two developed hypogammaglobulinemia. One patient developed steroid myopathy and another died during the follow-up period from clostridium difficile infection.

\section{Discussion}

This retrospective case series demonstrates that ANCA-positive and -negative vasculitis patients presenting with severe renal disease can achieve high rates of remission when treated with rituximab and glucocorticoids without cyclophosphamide. All patients in our cohort achieved remission. Approximately, $71 \%$ of patients who required dialysis at presentation were dialysis independent at 6 months, and 1 patient in our cohort experienced a relapse with renal involvement during the follow-up period.

Remission rates are likely similar, if not higher, in patients treated with rituximab-based induction therapy regimens compared with those treated with cyclophosphamide regardless of the degree of renal dysfunction. The RAVE trial demonstrated that $64 \%$ of patients treated with rituximab compared with $53 \%$ of those treated with cyclophosphamide achieved remission at 6 months, and patients responded similarly to either form of induction when they had renal involvement $[3,8]$. Although this trial excluded patients with serum creatinine $>4 \mathrm{mg} /$ $\mathrm{dl}, 31 \%$ of patients had eGFR $<30 \mathrm{ml} / \mathrm{min} / 1.73 \mathrm{~m}^{2}$. In one cohort of 155 patients with eGFR $<15 \mathrm{ml} / \mathrm{min} / 1.73 \mathrm{~m}^{2}$ treated predominantly with glucocorticoids and cyclophosphamide at induction, approximately $51 \%$ of patients were free of dialysis without any evidence of active vasculitis at 4 months [9]. The RITUXVAS study included patients with severe renal dysfunction; however, pa- tients who received rituximab for induction also received 2 doses of pulsed cyclophosphamide. Both arms in this study achieved approximately $80 \%$ remission rates at 1 year [4]. Given our cohort achieved a $100 \%$ remission rate by 6 months, it is plausible and consistent with prior studies that rituximab induction yields remission rates comparable to those yielded by cyclophosphamide.

Dialysis independence rates were similar in our cohort compared with dialysis-dependent patients treated with cyclophosphamide. Pepper et al. followed 41 dialysis-dependent patients treated with intravenous cyclophosphamide and glucocorticoids for induction therapy [10]. In this cohort, $29.3 \%$ remained dialysis dependent at 3 months and 35\% were dialysis dependent at 1 year. This is similar to our findings of $29 \%$ of patients who remained dialysis dependent at 6 months.

Patients treated with rituximab have similar, if not fewer, adverse events compared with those treated with cyclophosphamide. In Pepper et al. [10], 21\% developed leukopenia and $41 \%$ experienced infectious complications when treated with cyclophosphamide. The leukopenia and infection rates were much lower in our cohort at $15.4 \%$ for both adverse events, respectively. In addition, mortality due to treatment or disease-related causes was approximately $17 \%$ in patients with severe renal disease who were treated predominantly with cyclophosphamide and glucocorticoids, which is similar to findings in other studies, but much higher than what is reported in this study [10]. The RAVE trial, however, demonstrated similar adverse event rates in patients treated with cyclophosphamide compared with those treated with rituximab, and this may be due to the ability to capture adverse events more accurately in a trial setting as compared to that of a chart review.

There are several limitations to this study. This cohort consists of Caucasians, most of whom are male. This population has lower rates of treatment resistance compared with African-Americans and women, which may skew our data to appear more favorable in achieving remission [7]. The sample size is small, and the follow-up time was relatively short; therefore, relapse rates may be underestimated. As a retrospective case series, the study is limited by the documentation in clinical records, and there is no direct comparison group. Finally, pathologic classifications were based on reports, and specimens were not centrally interpreted.

This is the first study that demonstrates the effectiveness and safety of rituximab and glucocorticoids for induction of remission in small vessel vasculitis patients presenting with severe renal disease. Further investiga- 
tion with larger study cohorts comparing rituximab and cyclophosphamide induction therapy in patients with severe renal disease is needed to support the use of rituximab in this population.

\section{Disclosure Statement}

Zdenka Hruskova, MD, $\mathrm{PhD}$ : received lecture fees/honoraria from GSK and Biogen Idec. Marten Segelmark, MD: received lecture fees from Roche. Vladimir Tesar, MD, PhD, MBA: received lecture fees and was part of the advisory board of Amgen, AbbVie, Baxter, ChemoCentryx, Fresenius and GSK. David R.W. Jayne, MD, FRCP: received research grant and consulting and lecture fees from Roche/Genentech. Duvuru Geetha, MD, MRCP (UK), is a Consultant for Genentech. The other authors have no disclosures.

\section{Acknowledgements}

Funding for this project was provided by the Donald B. and Dorothy L. Stabler Foundation.

\section{References}

1 Franssen CF, Stegeman CA, Kallenberg CG, et al: Antiproteinase 3- and antimyeloperoxidase-associated vasculitis. Kidney Int 2000; 57:2195-2206.

2 Gómez-Puerta JA, Quintana LF, Stone JH, Ramos-Casals M, Bosch X: B-cell depleting agents for ANCA vasculitides: a new therapeutic approach. Autoimmun Rev 2012;11: 646-652.

3 Jones RB, Tervaert JW, Hauser T, et al: Rituximab versus cyclophosphamide in ANCA-associated renal vasculitis. N Engl J Med 2010; 363:211-220.

4 Stone JH, Merkel PA, Spiera R: Rituximab versus cyclophosphamide for ANCA-associ- ated vasculitis. N Engl J Med 2010;363:221232.

5 Radhakrishnan J, Cattran DC: The KDIGO practice guideline on glomerulonephritis: reading between the (guide)lines - application to the individual patient. Kidney Int 2012;82:840-856.

6 Levey AS, Bosch JP, Lewis JB, et al: A more accurate method to estimate glomerular filtration rate from serum creatinine: a new prediction equation. Modification of diet in renal disease study group. Ann Intern Med 1999; 130:461-470.

7 Hogan SL, Falk RJ, Chin H, et al: Predictors of relapse and treatment resistance in anti- neutrophil cytoplasmic antibody-associated small-vessel vasculitis. Ann Intern Med 2005; 143:621-631.

8 Geetha D, Specks U, Stone JH, et al: Rituximab versus cyclophosphamide for ANCAassociated vasculitis with renal involvement. J Am Soc Nephrol 2015;26:976-985.

9 Lee T, Gasim A, Derebail VK, et al: Predictors of treatment outcomes in ANCA-associated vasculitis with severe kidney failure. Clin J Am Soc Nephrol 2014;9:905-913.

10 Pepper RJ, Chanouzas D, Tarzi R, et al: Intraveous cyclophosphamide and plasmaphereisis in dialysis-dependent ANCA-associated vasculitis. Clin J Am Soc Nephrol 2013;8:219-224. 